\title{
Review on molnupiravir as a promising oral drug for the treatment of COVID-19
}

\author{
Elham Zarenezhad $\mathbb{D}^{1} \cdot$ Mahrokh Marzi $^{1}$
}

Received: 10 October 2021 / Accepted: 16 December 2021 / Published online: 3 January 2022

(c) The Author(s), under exclusive licence to Springer Science+Business Media, LLC, part of Springer Nature 2022

\begin{abstract}
During the COVID-19 pandemic, various drug candidates have been developed, molnupiravir (MK-4482 and EIDD-2801), which is a new orally anti-viral agent under development for the treatment of COVID-19, is under study in the final stage of the clinical trial. Molnupiravir enhances the replication of viral RNA mutations in animals and humans. Due to the high demand for the synthesis of this drug, it was essential to develop an efficient and suitable synthetic pathway from raw material. In this study, molecular docking analysis on molnupiravir is examined also, the mechanism of action (MOA) and the recent synthetic pathway is reported. This review will be helpful to different disciplines such as medicinal chemistry, organic chemistry, biochemistry, and pharmacology.
\end{abstract}

\section{Graphical Abstract}

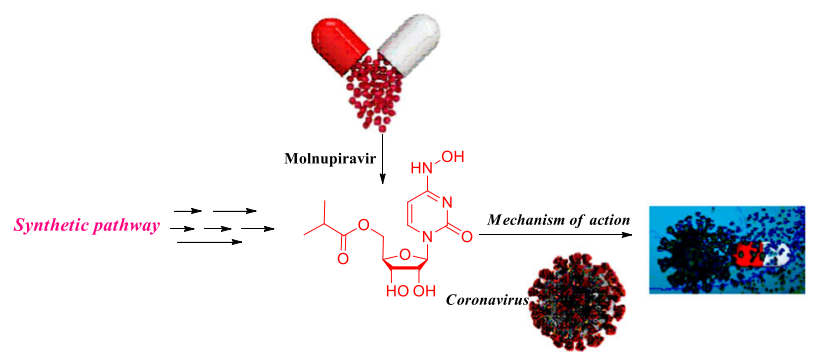

Keywords COVID-19 $\cdot$ Molnupiravir $\cdot$ Mechanism of action $\cdot$ Synthetic pathway $\cdot$ Molecular docking

\section{Abbreviation \\ (ATP) Adenosine triphosphate \\ (AGILE) is a randomized multi-arm, multi-dose, Phase $\mathrm{Ib} / \mathrm{II}$ a platform in the UK using a seamless Bayesian adaptive design 2 to determine the safety, activity, and optimal dose of multiple \\ (CD) SARS-CoV-2 candidate therapeutic targets. \\ (CTP)}

Elham Zarenezhad

El.zarenezhad@gmail.com

$\triangle$ Mahrokh Marzi

M.mahrokh89@gmail.com

1 Noncommunicable Diseases Research Center, Fasa University of Medical Sciences, Fasa, Iran

(DBRPC) Double-blind, randomized, placebo-controlled

(DBU) 1,8-diazabicyclo[5.4.0]undec-7-ene

(DMAP) 4-(N, N-dimethylamino)pyridine

(DMF- Dimethylformamide dimethyl acetal

DMA)

(DMP) 2,2-dimethoxypropane

$\left(\mathrm{Et}_{3} \mathrm{~N}\right) \quad$ Triethylamine

(EUA) Emergency use authorization

(+gRNA) Positive-stranded genomic RNA

(-gRNA) Negative-strand genomic RNA

(HMDS) Hexamethyldisilazane

(i-PrOH) 2-Propanol

(MeCN) Methyl cyanide

(MNP) Incorporation of molnupiravir as the monophosphorylated MNP

(MTP) NHC triphosphate

(NA) Not applicable/available

(NHC) N-hydroxycytidine 
$\left(\mathrm{NH}_{2} \mathrm{OH}\right)$ Hydroxylamine

(OL) Open-label

$\left(\mathrm{POCl}_{3}\right)$ Phosphoryl chloride

(RdRp) RNA-dependent RNA polymerase

(RNA) Ribonucleic acid

(SARS- Severe acute respiratory syndrome

CoV-2) coronavirus 2

$(+$ sgmR- Positive-strand subgenomic mRNA

NA)

(THF) Tetrahydrofuran

(TMS) Trimethylsilyl

(UTP) Uridine triphosphate

\section{Introduction}

COVID-19 pandemic, which is caused by severe acute respiratory syndrome coronavirus 2 (SARS-CoV-2), a novel coronavirus $(\mathrm{CoV})$, has become a serious threat to public health. Until the end of March 8th, 2021, more than 115 million people were infected, and unfortunately almost 2.5 million people died all over the world [1]. In this regard, one of the helpful drugs for the treatment is molnupiravir which is an anti-viral drug with commercial cod (MK-4482 and EIDD-2801), and is administered to treat influenza. This prodrug has a nucleoside scaffold of N4hydroxycytidine [2, 3], which was first produced at Emory university with the cooperation of the university's drug innovation company and is developing by Merck company as a novel oral anti-viral drug for the treatment of COVID-19 [4]. The application of this drug on animal species demonstrated the success of molnupiravir in prevention of viral transmission and inhibition of SARS-CoV22 [5]. Based on an oral anti-viral ribonucleoside analog, this drug is regarded as $5^{\prime}$-isobutyrate prodrugs of directacting anti-viral ribonucleoside analog, EIDD-1931 or $\beta$-DN4-hydroxycytidine. In the plasma, molnupiravir is cleaved to release EIDD-1931. Intracellularly EIDD-1931 is phosphorylated by host kinases to its corresponding $5^{\prime}$-triphosphate, the active anti-viral agent [6, 7]. In animal models of various coronaviruses, influenza, Ebola virus infection demonstrated that EIDD-1931 inhibits replication of multiple RNA viruses successfully [7-9]. This oral drug with high potency toward SARS-CoV-2 infectious showed desirable safety and acceptable profile [10].

Phase 1 clinical trial demonstrated that molnupiravir as a novel oral anti-viral drug has been very good tolerated and safe for some healthy volunteers [11]. Patients with mild to moderate COVID-19 were administered twice a day for five days in Phase 2 trial, namely placebo-controlled, doubleblind, randomized, multicenter trial indicating that the drug reduces the transcription of SARS-CoV-2 and the rate of clearance of infectious virus and prevents the progression of COVID-19 and replication of SARS-CoV-2 successfully $[10,12]$. The results of the phase $2 / 3$ trial were presented at the European congress of clinical microbiology and infection disease [ECCMID]. Phase 2/3 clinical trial showed a promising drug for non-hospitalized patients with COVID19. Merck and Ridgeback Bio collaborate to develop of a new anti-viral compound, EIDD-2801 [13]. This review focuses on the mechanism of action and new synthetic pathway of molnupiravir as an anti-viral agent to provide insight into the logical synthesis of more effective molnupiravir as an antiviral candidate.

\section{Metabolism of molnupiravir}

Molnupiravir is an oral prodrug of N6-hydroxycytidine which was planned against influenza in 2019. With the advent of SARS-CoV-2, molnupiravir has shown strong anti-SARS-CoV-2 activity (in animal models and in vitro) [5]. Potent and elective antiviral inhibitors of coronaviruses containing SARS-CoV-2 are known among nucleosides and analog nucleotides with a wide range of antiviral activity, some of which have rapidly advanced in clinical trials for the treatment of COVID-19 [14] (Fig. 1, Table 1).

Unlike other drugs of COVID-19 with emergency use authorization (EUA), molnupiravir can be produced at a bigger scale. This drug doesn't need in-hospital settings and
Fig. 1 Structure of nucleoside analog of molnupiravir and its metabolic activation.

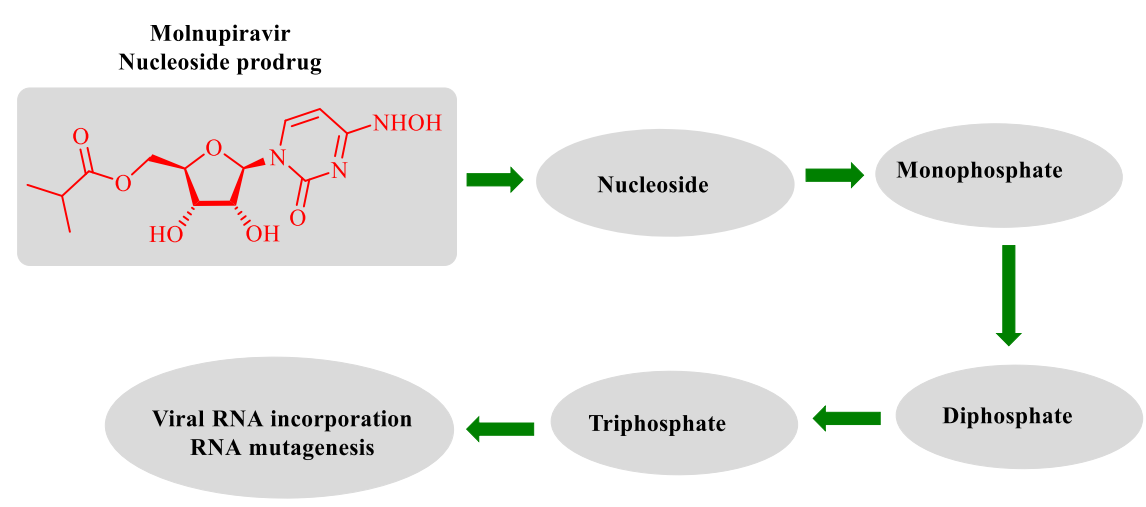


Table 1 Nucleoside analog of molnupiravir for the treatment of COVID-19. Status in

November 2020.

\begin{tabular}{|c|c|c|c|c|c|}
\hline $\begin{array}{l}\text { Nucleoside } \\
\text { drug }\end{array}$ & From & $\begin{array}{l}\text { Mechanism } \\
\text { of action }\end{array}$ & 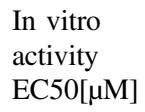 & $\begin{array}{l}\text { Animal } \\
\text { model } \\
\text { efficacy }\end{array}$ & $\begin{array}{l}\text { Clinical } \\
\text { dosing }\end{array}$ \\
\hline $\begin{array}{l}\text { Molnupiravir } \\
\text { (EIDD-2801; } \\
\text { MK-4482) }\end{array}$ & $\begin{array}{l}\text { Nucleoside } \\
\text { prodrug }\end{array}$ & $\begin{array}{l}\text { Viral RNA } \\
\text { mutagenesis }\end{array}$ & $0.05-0.3$ & Mouse & $\begin{array}{l}\text { Oral BID } \\
200-800 \\
\mathrm{mg}\end{array}$ \\
\hline
\end{tabular}

cold transportation for administration. The evidence has shown that molnupiravir is better tolerated and safer in phase 1, 2, and 3 clinical trials, at least in the short term, without any significant side effects [15] (Table 2).

\section{Mechanism of action of molnupiravir}

Since the outbreak of the Coronavirus epidemic, several scientific projects have been launched to investigate measures against the new virus. Researchers has been developing different vaccines and drugs with various degrees of success. Molnupiravir was developed to treat influenza and was recognized as another candidate for antiviral drugs. Understanding the mechanism of molnupiravir at the molecular level is critical to the further development of antiviral drugs. The drug is activated through metabolism in the body. Once inside the cell, it becomes an RNA-like component. In the first step, RNA polymerase (the viral copy machine) incorporates these components into the RNA genome of the virus. In the next step, RNA-like components are paired with viral genetic material components. Viral RNA contains several mutations when it multiplies to produce new viruses, preventing the reproduction of pathogen. This viral drug causes mutations in other RNA viruses and prevents them from expansion [17]. Molnupiravir, a promising drug, is in the third phase of studies. When molnupiravir enters the cell, the active molnupiravir forms N-hydroxycytidine hydrate (NHC triphosphate (MTP)), which can be replaced by cytidine triphosphate (CTP) or uridine triphosphate (UTP) by RNAdependent RNA polymerase (RdRp) of SARS-CoV-2 (Fig. 2A). Initially, when RdRp uses positive-strand genomic RNA for synthesis sub-genomic RNA and negative-strand genomic RNA as a template, it regularly substitutes $\mathrm{M}$ for $\mathrm{U}$ or $\mathrm{C}$. In the next step, +gRNA or + sgmRNA (positive-strand subgenomic mRNA) can be used from RNA including $M$ as a template. Then mutations are formed in positive-stranded genomic RNA products due to the presence of $\mathrm{M}$ in negativestrand genomic RNA (Fig. 2B), and these products prevent the formation of healthy new viruses $[3,5,18]$. At the end of this two-step mechanism, the mechanism of molnupiravir and its activated type were shown resulting in RNA mutations through polymerases of other viruses (Fig. 2) [17, 19].

According to previous studies, molnupiravir-induced lethal mutagenesis was determined by a relatively high selectivity of MTP for incorporation as a CTP analog and the indiscriminate incorporation of either adenosine triphosphate (ATP) or GTP when MNP (incorporation of molnupiravir as the monophosphorylated MNP) is centralized in the template strand (at least a two-step mechanism). Downstream of C-to-U mutations generated by the erroneously incorporated AMP could subsequently template UTP incorporation. The replication fidelity required for viability is demarcated by mutations' agglomeration that pushes viral replication over the "error threshold". In the end, molnupiravir has excellent pharmacokinetic properties, including oral administration [20].

\section{Desirable dose and safety of molnupiravir in patients infected with the coronavirus}

AGILE is an Ib/IIa phase substrate for rapid evaluation of COVID-19 therapies [21]. In the experiment (NCT04746183), Khoo, Saye H., et al. [16] appraised the safety and desirable dose of molnupiravir in contribution with primary signaling infection. Patients (in groups of 6) were randomly assigned to 300,600 , and $800 \mathrm{mg}$ of oral molnupiravir administered twice a day for five days. If the probability of $30 \%$ or more of doselimiting toxicity (initial result) is more than $25 \%$ or more, it is unsafe. Secondary results represented clinical improvement, safety, virological reactions, and pharmacokinetics. Between July 17th and October 30th, 2020, eighteen participants (out of 103 participants screened) were registered, and it was shown that molnupiravir was well resisted at doses of 300,600 , and $800 \mathrm{mg}$ without severe side effects. Overall, molnupiravir was safe and well resisted in the second phase of assessment so it was recommended administrating a dose of $800 \mathrm{mg}$ twice a day for five days.

\section{Review of recent articles on synthetic methods of molnupiravir}

The main route for the synthesis of the compound molnupiravir was revealed by Emory University [22]. According to this pathway, molnupiravir was synthesized in five steps starting from uridine (4). In this study, the yield of the last two steps has not been reported; however, in total, this synthetic path has a maximum yield of $17 \%$. Initially, the 
vicinal diol was protected by acetone and sulfuric acid at room temperature $(18 \mathrm{~h})$ to produce acetonide $(5)$. Following the purification of compound (5) by trimethylamine, 4(N, N-dimethylamino) pyridine (DMAP) and triethylamine $\left(\mathrm{Et}_{3} \mathrm{~N}\right)$ were added to the reaction mixture. The mixture was cooled to $0{ }^{\circ} \mathrm{C}$, and then isobutyricacid anhydride (6) was gradually added, and the resulting mixture was warmed to room temperature. The compound (7) was dissolved in acetonitrile solvent and then was added to the reaction triethylamine (8 equiv) and 1,2,4-triazole (7 equiv). After cooling, the solution was treated by phosphoryl chloride $\left(\mathrm{POCl}_{3}\right)$ and warmed to room temperature. The corresponding triazole (8) was isolated by chromatography with a yield of $29 \%$. Then compound (9) was obtained by dissolving compound (8) in 2-Propanol (2-PrOH) and treating it with hydroxylamine $\left(\mathrm{NH}_{2} \mathrm{OH}\right)$ (with a yield of $60 \%$ ) at room temperature. Using neat formic acid, the study performed deprotection at room temperature and synthesized molnupiravir (10) that was finally crystallized and recrystallized using 2-PrOH/MTBE (Scheme 1) [22].

Vasudevan, N. et al. [23] reported a two-step pathway in the synthesis of molnupiravir, including esterification and hydroxamination of cytidine. This study showed a yield of $75 \%$, which is a significant improvement compared to the previously reported yield (17\%) [22]. The number of steps was reduced from five to two, and the available cytidine was replaced by the expensive uridine. In this study, with minor modification of reaction conditions, N(4)-hydroxycytidine (NHC, 12) was synthesized in a yield of $70 \%$. This is an important point that after concentration, pure NHC with simple crystallization directly from the reaction mixture at $50 \%$ isolated yield, and then avoid dihydroxamination with $\mathrm{NH}_{2} \mathrm{OH} \_\mathrm{H}_{2} \mathrm{SO}_{4}$ in $\mathrm{iPrOH}$ altogether when it was investigated transamination of cytidine isobutyryl ester (13). Molnupiravir (10) was created from compound (13) with $96 \%$ isolated yield, indicating the survival of direct hydroxamination from both cytidine reaction pathways. In the first esterification, molnupiravir was obtained with a yield of $75 \%$, and its yield was $37 \%$ when hydroxyamination was done (Scheme 2).

Benkovics, T. et al. [24] reported the shortest synthetic path possible to molnupiravir (three-step pathway), which was activated through the invention of a new biocatalytic waterfall and the final density step (Scheme 3). Each step was performed at a yield of more than $95 \%$ and was only used from available reagents and easy functioning. This new route is $70 \%$ shorter than the original routes [22, 23] and about seven times higher than the overall yield. This synthesis method started with the elective esterification of ribose at the primary alcohol and the use of isobutyric anhydride (6) as an isobutyryl donor. According to the hypothesis, the selectivity for the product was broad, and a small amount of any side-products was created. The 
Fig. 2 Mechanism of action of molnupiravir. A Conversion of molnupiravir as a substrate to the active form in the cell. B Different forms of tautomeric of NHC-triphosphate (MTP). The hydroxylamine form (2) allows MTP to pair with $\mathrm{G}$ and acts like $\mathrm{C}$, while the oxime form (3) allows it to pair with $\mathrm{A}$ and acts like U. C Molnupiravir-induced RNA mutagenesis in the twostep model. In the first step, RdRp uses from +gRNA and regularly substitutes $\mathrm{M}$ for $\mathrm{U}$ or C. In the second step, mutations are formed in positive-stranded genomic RNA products due to the presence of $\mathrm{M}$ in negativestrand genomic RNA.
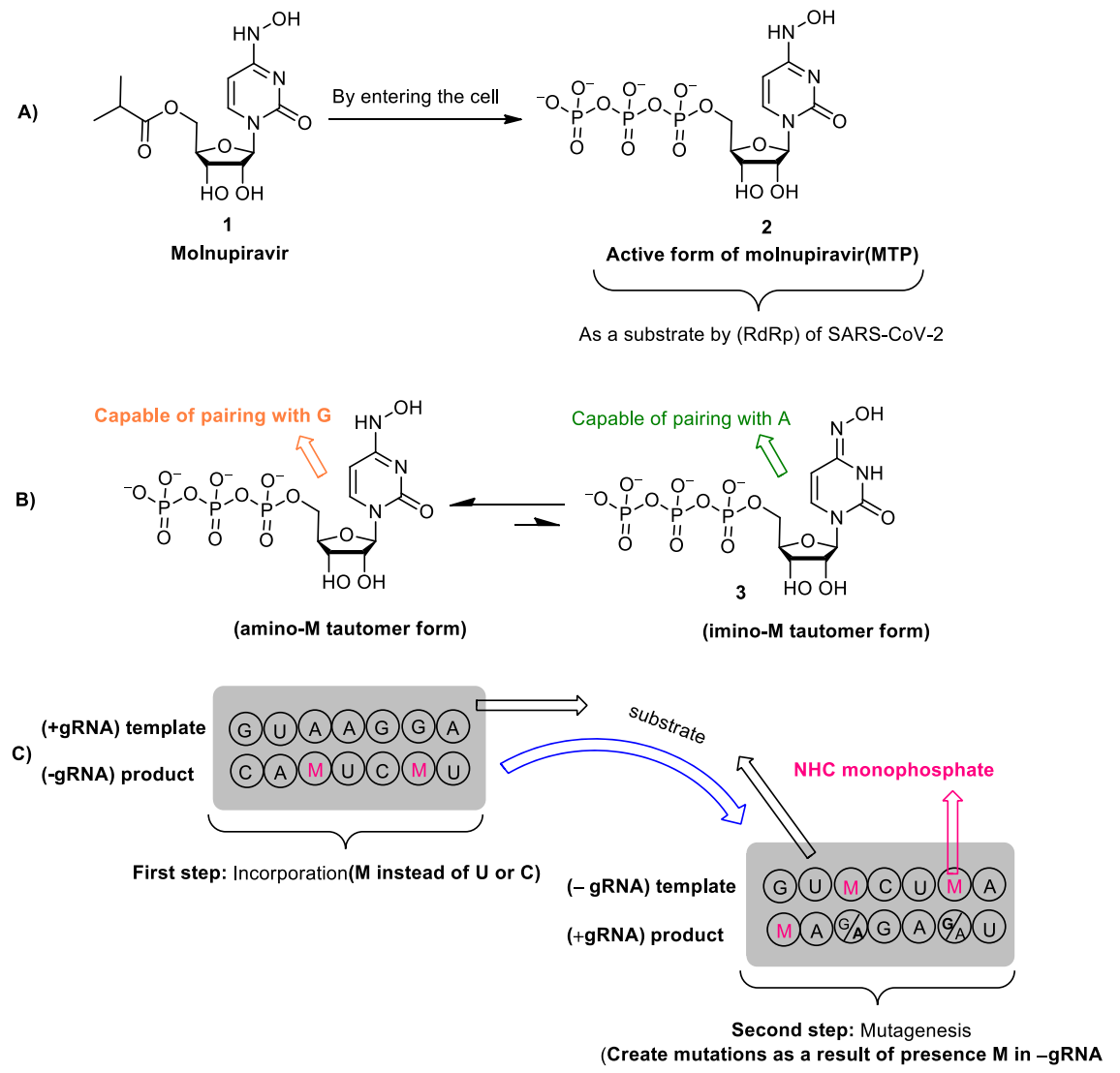

esterification of ribose in acetone (10 wt\% Novozym 435) supplied the desirable 5-isobutyryl ribose in $94 \%$ yield. Then it examined the 1-phosphorylation to transform (16) to 1-phosphate (17) with an appropriate nucleoside phosphorylase [25]. With the presence of hexamethyldisilazane (HMDS), quantitative yield almost occurred; however, it did not produce any significant side-products in the transformation of (19) to molnupiravir. With the elimination of inorganic species, the trimethylsilyl (TMS) groups were easily cleaved by modifying the $\mathrm{pH}$, after that the product was crystallized, and a new three-step synthesis was completed producing molnupiravir (10) in high-yield.

Steiner, A., et al. [26] designed and developed a simple rearrangement of the reaction series to improve the synthesis of molnupiravir against SARS-CoV-2 virus compared to the previous method [22]. The main advantage of this method compared to the main route [22] was the increase in yield from $17 \%$ to $61 \%$ and the reduction of isolation and purification steps. Moreover, a continuous flow method was developed for the final protection of acetonide, indicating high reproducibility and selectivity. Reese et al. [27] began the synthesis of molnupiravir by triazulation. By changing the triethylamine base to $\mathrm{N}$-methylpyrrolidine and introducing the triazole moiety in the first stage, the yield of compound (20) increased from $74 \%$ to $88 \%$. Then methanol was removed by a stepwise azeotropic distillation after stirring of (20) with 2,2-dimethoxypropane (DMP) and $\mathrm{H} 2 \mathrm{SO} 4$ in $\mathrm{MeCN}$ for $30 \mathrm{~min}$ at room temperature. This protocol showed that only (1.1 equiv) of isobutyric anhydride was required for a complete conversion (21). Compound (8) was created after extractive work-up (quantitative yield and $\geq 99 \%$ HPLC purity). Compound (9) was obtained by stirring (8) in 2-Propanol (iPrOH) at room temperature with (1.5 equiv) (Scheme 4$)$.

Ahlqvist, Grace P et al. [28] described a two-step supplycentered and chromatography-free synthesis of molnupiravir from cytidine. By undergoing transamination to yield, the final medicine product followed a selective enzymatic acylation. These two steps have been promising and were accomplished on a decagram scale; that is the first step was accomplished at $200 \mathrm{~g}$ and the second step was accomplished at $80 \mathrm{~g}$ compared to previous work in which the first step was accomplished at $5 \mathrm{~g}$ and the second step was accomplished at $1 \mathrm{~g}$ [23] (Scheme 5). In total, molnupiravir was obtained by a $41 \%$ isolated yield and was less costly than the original route recorded [29].

Snead et al. developed a four-step method for molnupiravir in which cytidine was the starting material [30]. This synthesis started with the constitution of the acetonide by 2,2-dimethoxypropane in acetone with $\mathrm{H} 2 \mathrm{SO} 4$ (as the 
Scheme 1 Synthetic pathway revealed from molnupiravir by Emory University in 2019.

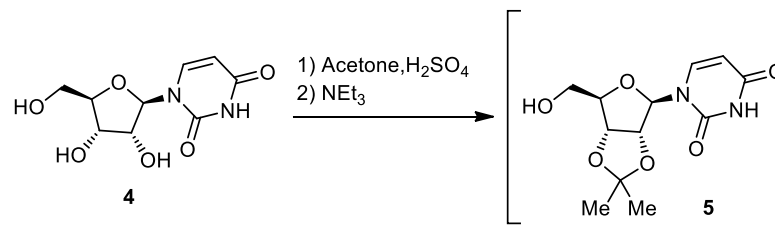<smiles>CC(C)C(=O)OC(=O)C(C)C</smiles><smiles>[Y6]C1(C)O[C@@H]2[C@H](O1)[C@H](n1ccc(-n3cncn3)nc1=O)O[C@@H]2COC(=O)C(C)C</smiles><smiles>[Y6]C1([Y6])O[C@H]2[C@@H](COC(=O)C(C)C)O[C@@H](n3ccc(NO)nc3=O)[C@@H]2O1</smiles><smiles>CC(C)C(=O)OCC1OC(n2ccc(NO)nc2=O)[C@H](O)[C@@H]1O</smiles>

MoInupiravir

$17 \%$ Overall Yield

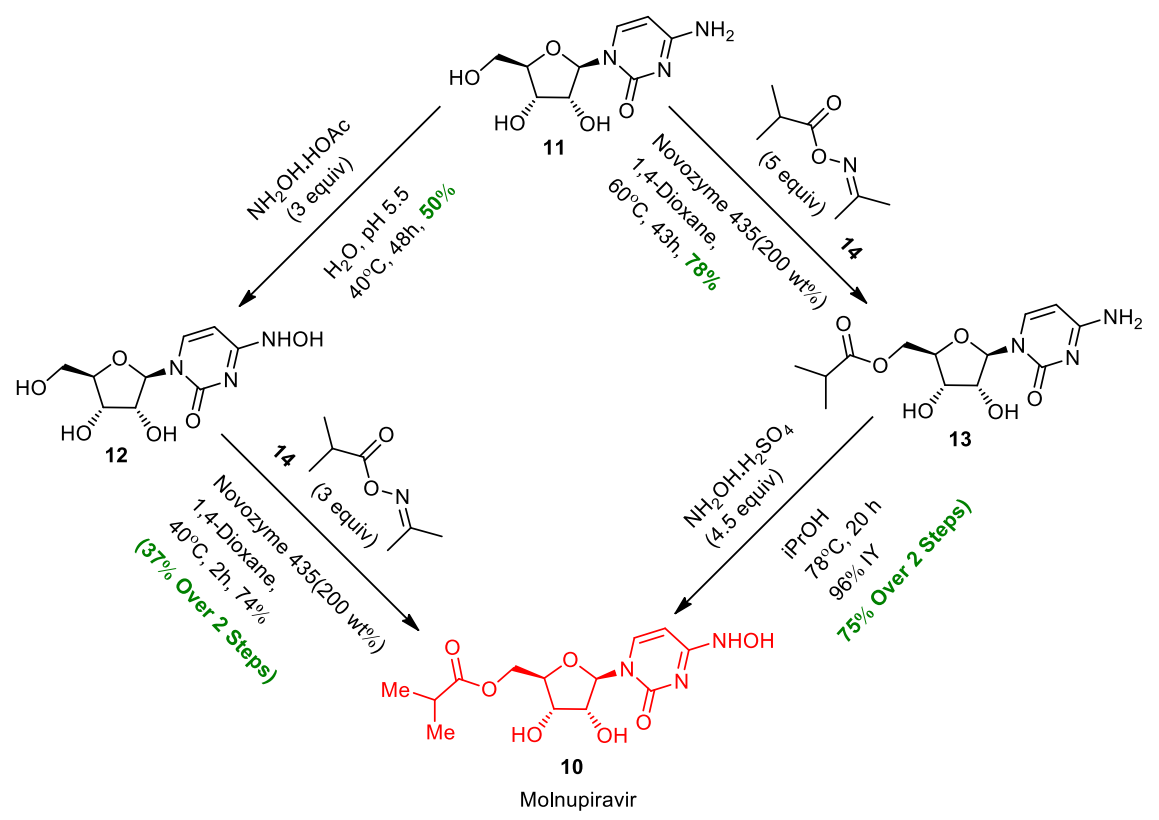

Scheme 2 Synthesis pathway of molnupiravir from cytidine. catalyst). Then acetonide (22) was separated from the reaction mixture after precipitation with a yield of $98 \%$. Reaction with isobutyric acid anhydride produced ester (23), after flash chromatography, obtained $78 \%$ yield by using 1,8-diazabicyclo [5.4.0] undec-7-ene (DBU) and catalytic 4-(N, N-dimethylamino) pyridine (DMAP) in acetonitrile. Hydroxyamination was performed in $70 \%$ aqueous 2-PrOH using hydroxylamine sulfate at $72-73{ }^{\circ} \mathrm{C}$ to form compound (9) in $96 \%$ yield. Protection of acetonide in formic acid was performed at room temperature. After 
flash chromatography, compound (10) was separated with $98 \%$ purity in $60 \%$ yield. In total, the yield was $41 \%$ during the three-step route and $44 \%$ within the four-step pathway (Scheme 6).

Synthesis of molnupiravir from cytidine (in four steps) was reported by $\mathrm{Hu} \mathrm{T}$ et al. at a yield of $70 \%$ and only one separation in the end [31]. In this method, dimethylformamide dimethyl acetal (DMF-DMA) is used to protect the

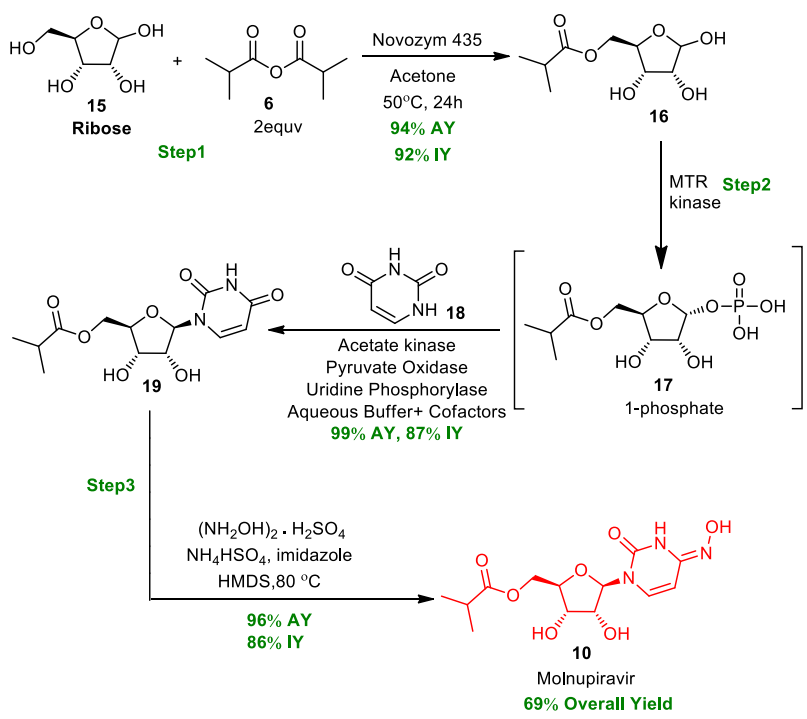

Scheme 3 A new route for the synthesis of molnupiravir from (ribose + uracil) by Benkovics et al. diol (removed easily without ester hydrolysis) and activate the amine. The synthesis began by cytidine therapy with DMF-DMA using pyridine (10 equiv) in Tetrahydrofuran (THF). Esther (26) was obtained by adding isobutyric acid anhydride (6), triethylamine, dichloromethane, and DMAP $(5 \mathrm{~mol} \%)$ at room temperature. After the reaction was complete, compound (27) was produced by adding ethanol and protecting the diol. After evaporation, by adding hydroxylamine sulfate and $70 \% 2$ - propanol/water, the reaction mixture was heated for $18 \mathrm{~h}$ to $78^{\circ} \mathrm{C}$. The reaction mixture was cooled, and the two layers were separated. The organic layer focused on dryness, and compound (10) was crystallized by 2-methyltetrahydrofuran (Scheme 7).

Burke A et al. [32] have expanded a brief and impressive biocatalytic synthesis of N-hydroxy-cytidine (12), an essential intermediate for the generation of molnupiravir (10). This study was performed by the transformation of cytidine (11) to compound (12) by cytidine deaminase (CD). Here, the raw material of cytidine was substituted for uridine due to its lower cost. As predicted, increasing the concentration of $\mathrm{NH}_{2} \mathrm{OH}$ led to the improved conversion of $\mathrm{N}$-hydroxycitidine (12). The advantage of CD is that it easily accepts high substrate loadings and 50\% hydroxylamine in water as a reaction solvent, on the other hands, its lyophilization is beneficial for bioproduction processes and will not reduce their activities significantly. $200 \mathrm{mM}$ cytidine is completely transformed to a 6: 1 mixture of N-hydroxy-cytidine (12) and uridine by $50 \% \mathrm{NH}_{2} \mathrm{OH}$. The final target was to abrogate
Scheme 4 An improved protocol for the synthesis of EIDD-2801 by Steiner A et al. (starting from uridine).

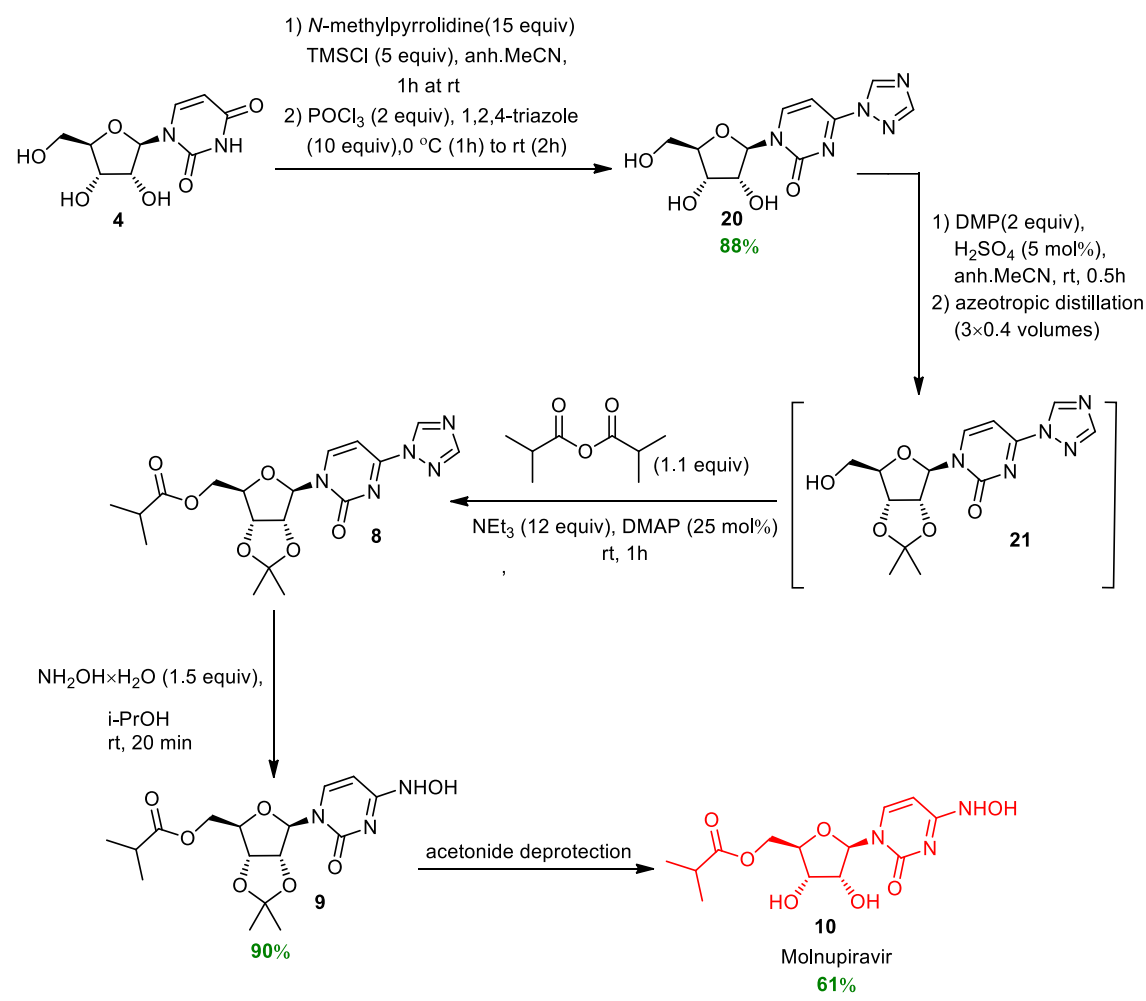


hydrolytic activity while concomitantly improving the yield of hydroxylamine with cytidine amination. In this work, the ratio of (12) to uridine has been increased through the direct evolution of CD. Cytidine hydrolysis activity was reduced by applying the $\mathrm{T} 123 \mathrm{G}$ mutation near the active site and maintaining the desired amination activity (Scheme 8).

Paymode DJ et al. [33] reported a two-step synthesis of molnupiravir (10) and developed applied reaction and filtration conditions towards the production route. Since cytidine (11) was used as the available starting material, molnupiravir was obtained by straight hydroxamination of the cytosine ring and esterification of the sugar's primary alcohol. This study aims to achieve an improved path with the desired production profile. Both reactions could achieve a yield of $90 \%$ by understanding the by-products and the mechanism of formation. Finally, the overall yield of the isolated product was improved by $23 \%$ (60\% of $37 \%$ ) with the product isolated by crystallization rather than chromatography. In this reaction, solvents such as water and 2-methyltetrahydrofuran

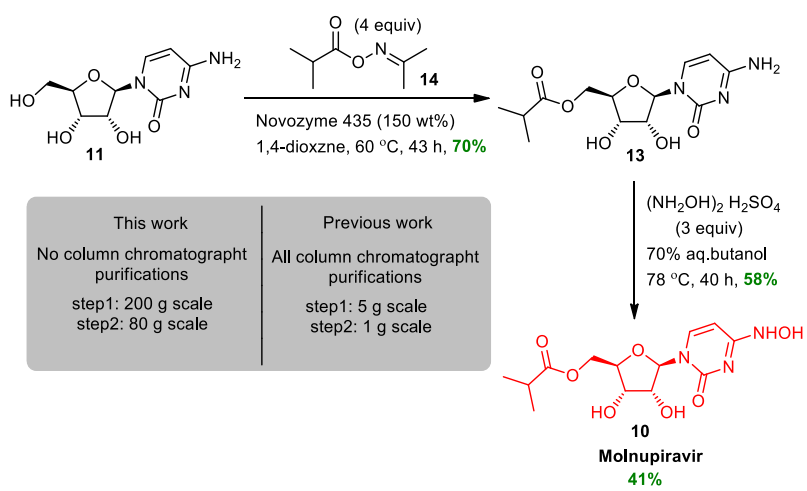

Scheme 5 Advances in the large-scale synthesis of molnupiravir from cytidine by Ahlqvist, Grace $\mathrm{P}$ et al. (i.e., environmentally friendly solvents) were used, and the solvent consumption was reduced tenfold ( 7 volumes out of 68 volumes). The acylation was carried out by an "off-theshelf" enzyme (CAL-B), and enzyme loading was decreased tenfold (200-20 wt\%). Reactions were increased to NHC $(500 \mathrm{~g})$, and molnupiravir $(100 \mathrm{~g})$ and terminal API with $99.4 \%$ purity were produced by main part of remained active drug, NHC (0.6\%) (Scheme 9).

Gopalsamuthiram V et al. [34] have expressed synthesis of molnupiravir from cytidine in four steps in the form of scale (Scheme 10, Table 3). The uniqueness of this method is its chemical nature, which includes eco-friendly solvents such as isopropanol, acetone, acetonitrile, water and cheap reagents. Isolation of all intermediates by recrystallization and aqueous acid treatment improved purification and isolation procedures compared to previously reported work [30]. In the first step, compound (22) is isolated straight from the reaction by washing and filtration, and then in the next step, the organic layer is washed with $10 \%$ acetic acid and formed compound (23). In the third step, (9) is created from isopropyl acetate by recrystallization of the crude, and in the next step, molnupiravir is produced by recrystallization of water. Ester formation, hydroxamination and deprotection were performed on multigram scale. In this work, molnupiravir (10) was obtained in a yield of $36-41 \%$ and an average purity of $98 \%$ wt $\%$ (Table 3 ).

\section{Molecular docking of molnupiravir to the nsp12-nsp7-nsp8 linked to the template- initiator RNA and shape of remdesivir triphosphate (RTP)}

$\beta$-D-N4-hydroxycytidine-5'-isopropyl ester (molnupiravir) is a NHC of oral bioavailability analogous to remdesivir; both
Scheme 6 The pathway of cytidine to molnupiravir in three or four steps by Snead et al.<smiles>Nc1ccn(C2OC(CO)C(O)C2O)c(=O)n1</smiles>

11
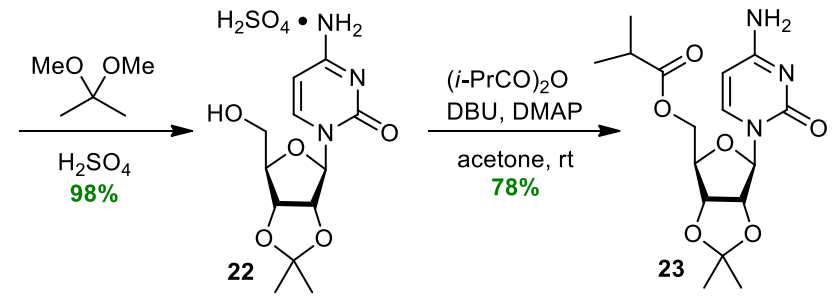

$\mathrm{NH}_{2} \mathrm{OH} . \mathrm{H}_{2} \mathrm{SO}_{4}$ $70 \% 2-\mathrm{PrOH}$ $30 \% \mathrm{H}_{2} \mathrm{O}$ $72-73{ }^{\circ} \mathrm{C}, 96 \%$

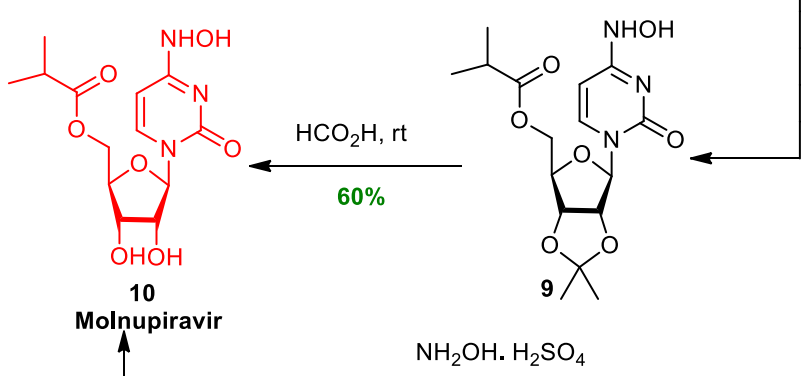

$60 \% 2-\mathrm{PrOH} / 40 \% \mathrm{H}_{2} \mathrm{O}$ 
Scheme 7 Four-step singleisolation route to molnupiravir by $\mathrm{Hu} \mathrm{T}$ et al.

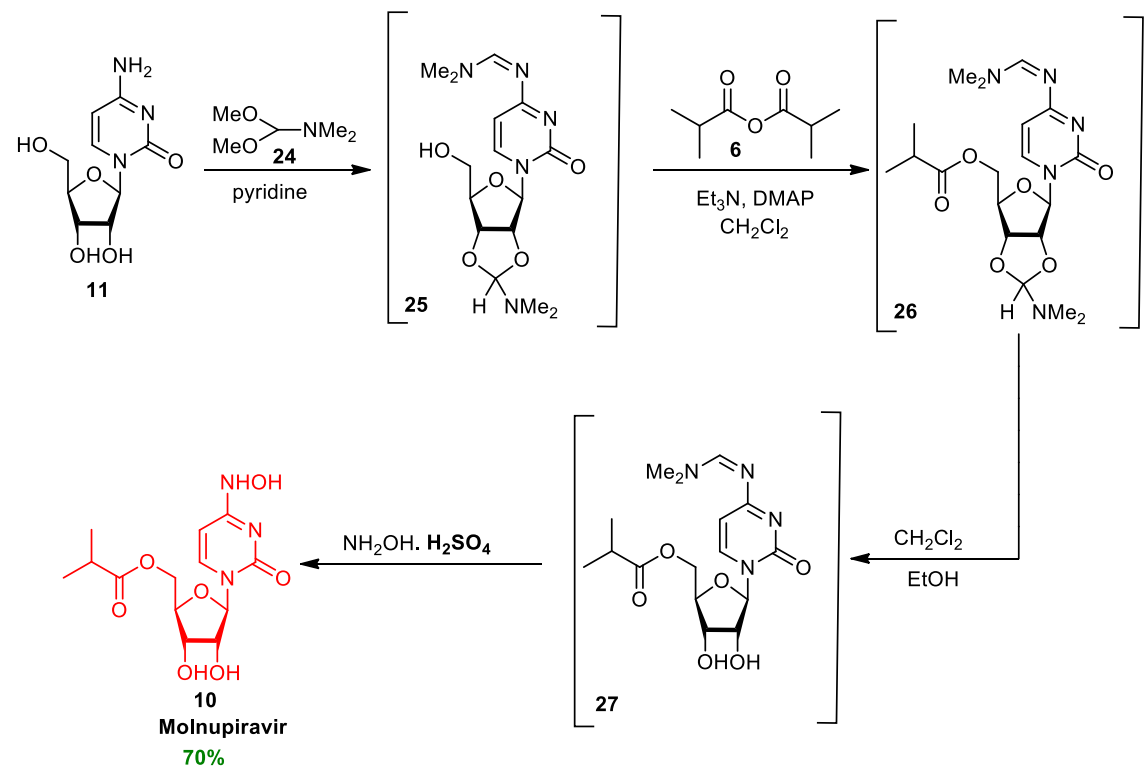

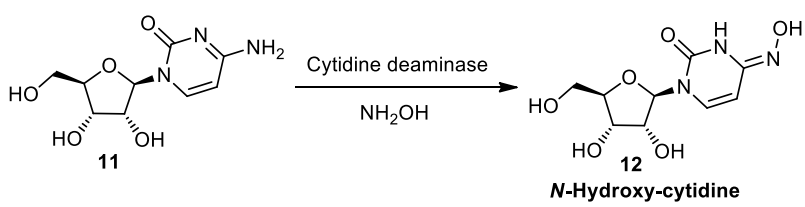

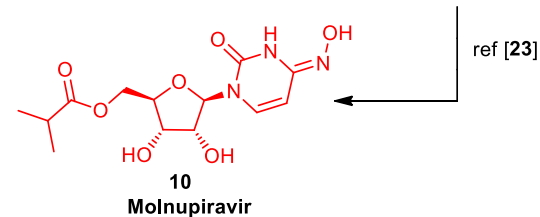

Scheme 8 Synthesis of molnupiravir by using a biocatalytic approach to a key intermediate.

drugs act by imitating ribonucleosides [5]; thus, molnupiravir was docked within the remdesivir binding site of the RdRp of SARS-CoV-2. AutoDock instrumentations were used for molecular docking to dock the molnupiravir to the nsp12 binding hole, where it exerts its antiviral target by providing copy errors during viral RNA replication $[35,36]$. The nsp12nsp7-nsp8 complex contained the $\mathrm{Mg}^{2+}$ and RNA catalytic ions. PDB ID: 7BV2 by remdesivir was co-crystallized. For the molnupiravir docking studies, the identical binding grid was selected. The ligands and protein were created by using the MGL instrumentations. Kollman and Hydrogens charges were appended to the protein, and were then added to molnupiravir, Gaisteger, and hydrogen charges to be prepared. The grid with $0.375-\AA$ grid spacing was adjusted as $X=42$, $\mathrm{Y}=46$, and $\mathrm{Z}=52$. At this point, the ligand and protein were docked, and 100 binding cases were produced for the analysis. For further analysis, the best binding cases were chosen that displayed interactions with the main catalytic remainder. Therefore, docking were identified the interactions among the ligands and complex. Overall, with molnupiravir interacted of 65 residues from nsp12 (Table 4) (Fig. 3) [37].

\section{Conclusions}

Nowadays, the COVID-19 pandemic is one of the world's problems that has caused a lot of death every year. Many researchers from different fields of study, such as organic chemist, medicinal chemist, pharmacologist, etc., focused on discovering and developing new pharmaceuticals against novel coronavirus (CoV). Evaluating an effectual small-molecule therapeutic target will be the urgent therapeutic strategy. Molnupiravir as an oral antiviral agent displayed a promising compound for non-hospitalized patients with COVID-19. Phases 1, 2, and 3 clinical trials resulted molnupiravir remarkably reduced the risk of hospitalization or death in adults experiencing mild or moderate COVID-19. According to emerging findings, molnupiravir may be proved to be a global game-changer in the fight against SARS-CoV-2. In conclusion, the preparation of this potent antiviral drug has attracted attention all over the world.

\section{Availability of data and materials}

The datasets used and analyzed during the current study are available from the corresponding author on reasonable request. We have presented all data in the form of figures. 
Scheme 9 M4ALL's approach to molnupiravir from cytidine.
Scheme 10 Acetonide approach to molnupiravir [30].
Table 3 Increase scale of the four-step series to molnupiravir.

\begin{tabular}{lllll}
\hline Step & Scale & $\begin{array}{l}\text { \% Corrected } \\
\text { isolated yield }\end{array}$ & $\begin{array}{l}\text { Area \% HPLC } \\
(260 \mathrm{~nm})\end{array}$ & $\begin{array}{l}\text { Wt \% by } \\
\text { NMR }\end{array}$ \\
\hline 1 & $100 \mathrm{~g}$ & $94 \%$ & $99.1 \%$ & $95 \%$ \\
& $300 \mathrm{~g}$ & $92 \%$ & $99.2 \%$ & $95.5 \%$ \\
2 & $150 \mathrm{~g}$ & $92 \%$ & $98.6 \%$ & $89 \%$ \\
& $140 \mathrm{~g}$ & $95.2 \%$ & $94 \%$ & $85.8 \%$ \\
3 & $130 \mathrm{~g}$ & $70 \%$ & $97.3 \%$ & $94 \%$ \\
& $120 \mathrm{~g}$ & $76 \%$ & $98.7 \%$ & $95 \%$ \\
4 & $80 \mathrm{~g}$ & $59 \%$ & $98.6 \%$ & $98.5 \%$ \\
& $100 \mathrm{~g}$ & $61 \%$ & $99.6 \%$ & $97.6 \%$ \\
\hline
\end{tabular}

1) $\left(\mathrm{NH}_{2} \mathrm{OH}\right)_{2} \cdot \mathrm{H}_{2} \mathrm{SO}_{4}$ (1.2 equiv.) $\mathrm{H}_{2} \mathrm{O}$ (2Volumes)<smiles>CC(C)C(=O)OCC1OC(n2ccc(NO)nc2=O)[C@H](O)[C@@H]1O</smiles>

2) Novozyme $435(20 w t \%)$ Acetone Isobut. Oxime Ester 2-Me THF (5 Volumes) $40^{\circ} \mathrm{C}, 16 \mathrm{~h}$, then $\mathrm{NH}_{2} \mathrm{OH}$ $71 \%(93 \%$ AY) $100 \mathrm{~g}$

Molnupiravir

$99.4 \%$ purity Overall Yield $60 \%$ of $37 \%$

\begin{tabular}{|c|c|c|c|c|c|c|c|}
\hline $\begin{array}{c}\text { Overall } \\
\text { Yield }\end{array}$ & $\begin{array}{c}\text { Step } \\
\text { Count }\end{array}$ & $\begin{array}{c}\text { SM } \\
\text { Price }\end{array}$ & $\begin{array}{c}\text { Solvent } \\
\text { Consumption } \\
\text { (Volumes) }\end{array}$ & $\begin{array}{c}\text { Enzyme } \\
\text { Loading }\end{array}$ & $\begin{array}{c}\text { Final Step } \\
\text { Scale }\end{array}$ & Isolation & Gen. \\
\hline $17 \%$ & 4 & $\begin{array}{c}\text { S140-170 } \\
\text { Uridine }\end{array}$ & not determined & $\begin{array}{c}\text { not } \\
\text { applicable }\end{array}$ & $6.5 \mathrm{~g}$ & Column & $\begin{array}{c}\text { Initial [22] } \\
\text { Synthesis }\end{array}$ \\
\hline $37 \%$ & 2 & $\begin{array}{c}\text { S50-60kg } \\
\text { Cytidine }\end{array}$ & 68 & $200 \mathrm{wt} \%$ & $1 \mathrm{~g}$ & Column & $\begin{array}{c}\text { M4All } \\
1^{\text {st }} \text { Gen }\end{array}$ \\
\hline $60 \%$ & 2 & $\begin{array}{c}\text { S50-60kg } \\
\text { Cytidine }\end{array}$ & 7 & $20 \mathrm{wt} \%$ & $100 \mathrm{~g}$ & Crystall- & M4All \\
ization & $2^{\text {nd }}$ Gen \\
\hline
\end{tabular}<smiles>Nc1ccn(C2OC3C(O)C2C3O)c(=O)n1</smiles>

11

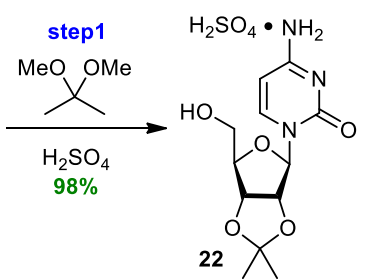

$22 X$

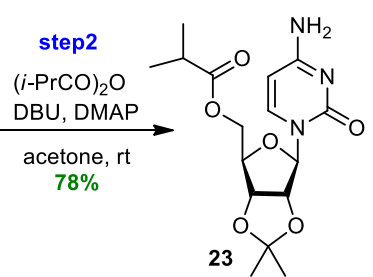

23

$\mathrm{NH}_{2} \mathrm{OH} . \mathrm{H}_{2} \mathrm{SO}_{4}$ $70 \% 2-\mathrm{PrOH}$ $30 \% \mathrm{H}_{2} \mathrm{O}$ $72-73{ }^{\circ} \mathrm{C}, 96 \%$

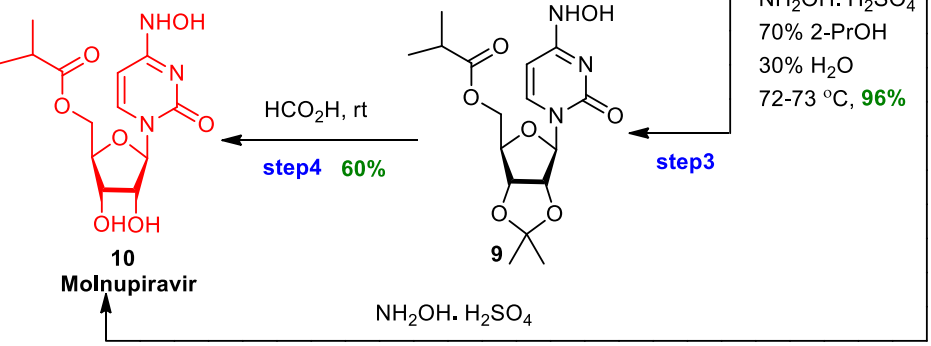

$60 \%$ 2-PrOH/ $40 \% \mathrm{H}_{2} \mathrm{O}$

Table 4 Intermolecular interactions of molnupiravir and nsp12 binding residues.

Molnupiravir-nsp 12

Types of interactions Affinity-enhancing Affinity-attenuating

Van der waals

2

interactions

Proximal interactions 239

5

Polar contacts

10

225

Hydrogen bonds

9

Aromatic contacts

2

Hydrophobic

13

contacts

Carbonyl interactions 2

3

Total number of

281

0

interactions 


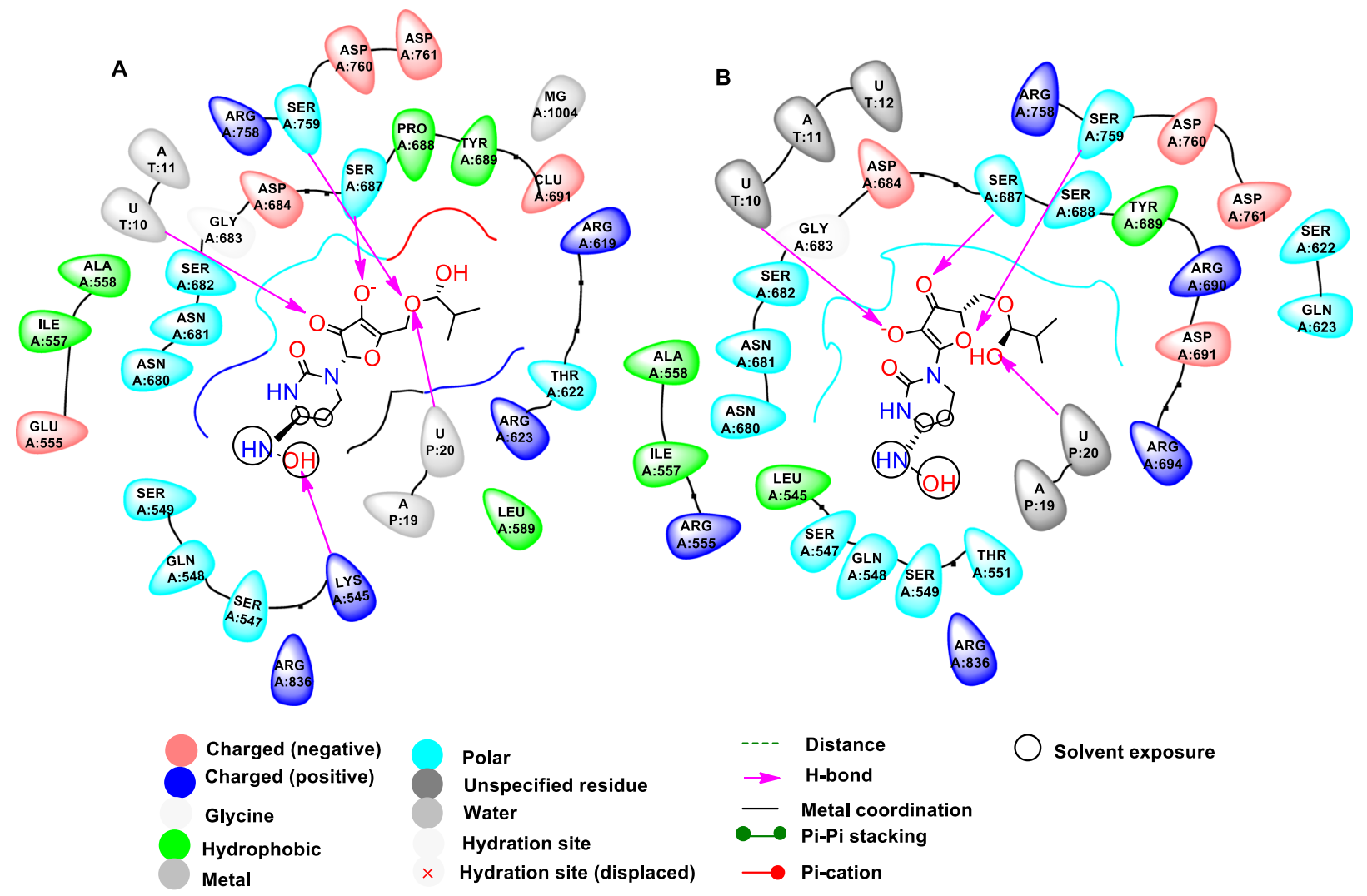

Fig. 3 Ligand interaction diagrams between nsp12-nsp7-nsp8-RNA complex and molnupiravir for high-score affinity enhancement and affinity attenuation schemes. Diagrams of two-dimensional ligand interactions between molnupiravir and the nsp12-nsp7-nsp8-RNA

Acknowledgements The authors would like to thank the support of the Noncommunicable Diseases Research Center, Fasa University of Medical Sciences (Grant No, 400092). The ethical committee has ethically approved this research; IR.FUMS.REC.1400.069.

\section{Compliance with ethical standards}

Conflict of interest The authors declare no competing interests.

Publisher's note Springer Nature remains neutral with regard to jurisdictional claims in published maps and institutional affiliations.

\section{References}

1. Grubaugh ND, Hodcroft EB, Fauver JR, Phelan AL, Cevik M. Public health actions to control new SARS-CoV-2 variants. Cell. 2021;184:1127-32. https://doi.org/10.1016/j.cell.2021.01.044.

2. Toots M, Yoon J-J, Cox RM, Hart M, Sticher ZM, Makhsous N, et al. Characterization of orally efficacious influenza drug with high resistance barrier in ferrets and human airway epithelia. Sci Transl Med. 2019;11. https://doi.org/10.1126/scitranslmed.aax5866.

3. Toots M, Yoon J-J, Hart M, Natchus MG, Painter GR, Plemper RK. Quantitative efficacy paradigms of the influenza clinical drug candidate EIDD-2801 in the ferret model. Transl Res. 2020;218:16-28. https://doi.org/10.1016/j.trsl.2019.12.002. complex for the top-scoring (A) affinity-enhancing design and (B) affinity-attenuating design are shown within a $6-\mathrm{A}^{\circ}$ distance. Various types of intermolecular interactions are labeled in legends [37].

4. Cross R. Merck \& Co. joins race for COVID-19 vaccines and therapies. Chemical \& Engineering News. 2020;98:12.

5. Sheahan TP, Sims AC, Zhou S, Graham RL, Pruijssers AJ, Agostini ML et al. An orally bioavailable broad-spectrum antiviral inhibits SARS-CoV-2 in human airway epithelial cell cultures and multiple coronaviruses in mice. Sci Transl Med. 2020;12. https:// doi.org/10.1126/scitranslmed.abb5883.

6. Hernandez-Santiago BI, Beltran T, Stuyver L, Chu CK, Schinazi RF. Metabolism of the anti-hepatitis $C$ virus nucleoside $\beta-d-N$ 4-hydroxycytidine in different liver cells. Antimicrob Agents Chemother. 2004;48:4636-42. https://doi.org/10.1128/AAC.48. 12.4636-4642.2004.

7. Painter GR, Bowen RA, Bluemling GR, DeBergh J, Edpuganti V, Gruddanti PR. et al. The prophylactic and therapeutic activity of a broadly active ribonucleoside analog in a murine model of intranasal venezuelan equine encephalitis virus infection. Antivir Res. 2019;171:104597. https://doi.org/10.1016/j.antiviral.2019.104597.

8. Agostini ML, Pruijssers AJ, Chappell JD, Gribble J, Lu X, Andres EL. et al. Small-molecule antiviral $\beta$-d-N 4-hydroxycytidine inhibits a proofreading-intact coronavirus with a high genetic barrier to resistance. J Virol. 2019;93:e01348-19. https://doi.org/ 10.1128/JVI.01348-19.

9. Reynard O, Nguyen X-N, Alazard-Dany N, Barateau V, Cimarelli A, Volchkov VE. Identification of a new ribonucleoside inhibitor of ebola virus replication. Viruses. 2015;7:6233-40. https://doi. org/10.3390/v7122934

10. Fischer WA, Eron JJ, Holman W, Cohen MS, Fang L, Szewczyk LJ, et al. Molnupiravir an Oral Antiviral Treatment for COVID- 
19. medRxiv. 2021. https://doi.org/10.1101/2021.06.17. 21258639.

11. Painter WP, Holman W, Bush JA, Almazedi F, Malik H, Eraut NC. et al. Human safety, tolerability, and pharmacokinetics of molnupiravir, a novel broad-spectrum oral antiviral agent with activity against SARS-CoV-2. Antimicrob Agents Chemother. 2021;65:e02428-20. https://doi.org/10.1128/AAC.02428-20.

12. Zarenezhad E, Behrouz S, Farjam M, Rad MS. A mini review on discovery and synthesis of remdesivir as an effective and promising drug against COVID-19. Russian J Bioorg Chem. 2021;47:609-21. https://doi.org/10.1134/S1068162021030183.

13. Development MaRBCtAaE-oNAC, https://www.businesswire. com/news/home/20200526005229/en/.

14. Annaliesa Anderson PJMA SARS-COV-2 ANTIVIRAL THERAPEUTICS SUMMIT REPORT. 2020.

15. Singh AK, Singh A, Singh R, Misra A. Molnupiravir in COVID-19: a systematic review of literature. Diab Metab Syndrome: Clin Res Reviews. 2021:102329. https://doi.org/10.1016/j.dsx.2021.102329.

16. Khoo SH, Fitzgerald R, Fletcher T, Ewings S, Jaki T, Lyon R, et al. Optimal dose and safety of molnupiravir in patients with early SARS-CoV-2: a Phase I, open-label, dose-escalating, randomized controlled study. J Antimicrob Chemother. 2021. https:// doi.org/10.1101/2021.05.03.21256309.

17. Kabinger F, Stiller C, Schmitzová J, Dienemann C, Kokic G, Hillen HS, et al. Mechanism of molnupiravir-induced SARSCoV-2 mutagenesis. Nature Structural \& Molecular Biology. 2021:1-7. https://doi.org/10.1038/s41594-021-00651-0.

18. Crotty S, Cameron CE, Andino R. RNA virus error catastrophe: direct molecular test by using ribavirin. Proc Natl Acad Sci. 2001;98:6895-900. https://doi.org/10.1073/pnas.111085598.

19. Gordon CJ, Tchesnokov EP, Schinazi RF, Götte M. Molnupiravir promotes SARS-CoV-2 mutagenesis via the RNA template. J Biol Chem. 2021:100770. https://doi.org/10.1016/j.jbc.2021.100770.

20. Malone B, Campbell EA. Molnupiravir: Coding for catastrophe. Nat Struct Mol Biol. 2021;28:706-8. https://doi.org/10.1038/ s41594-021-00657-8.

21. Griffiths G, Fitzgerald R, Jaki T, Corkhill A, Marwood E, Reynolds $\mathrm{H}$. et al. AGILE-ACCORD: a randomized, multicentre, seamless, adaptive phase I/II platform study to determine the optimal dose, safety and efficacy of multiple candidate agents for the treatment of COVID-19: a structured summary of a study protocol for a randomised platform trial. Trials. 2020;21:1-3. https://doi.org/10.1186/s13063-020-04473-1.

22. Painter GR, et al. N4-hydroxycytidine and derivatives and antiviral uses related thereto. 2019;WO2019113462A12019.

23. Vasudevan N, Ahlqvist GP, McGeough CP, Paymode DJ, Cardoso FS, Lucas T. et al. A concise route to MK-4482 (EIDD2801) from cytidine. Chem Commun. 2020;56:13363-4. https:// doi.org/10.1039/D0CC05944.

24. Benkovics T, McIntosh J, Silverman S, Kong J, Maligres P, Itoh $\mathrm{T}$, et al. Evolving to an ideal synthesis of molnupiravir, an investigational treatment for COVID-19. 2020. https://doi.org/10. 26434/chemrxiv.13472373.v1.
25. Birmingham WR, Starbird CA, Panosian TD, Nannemann DP, Iverson T, Bachmann BO. Bioretrosynthetic construction of a didanosine biosynthetic pathway. Nat Chem Biol. 2014;10:392-9. https://doi.org/10.1038/nchembio.1494.

26. Steiner A, Znidar D, Ötvös SB, Snead DR, Dallinger D, Kappe CO. A high-yielding synthesis of EIDD-2801 from Uridine. Eur J Org Chem. 2020;2020:6736. https://doi.org/10.1002/ejoc. 202001340.

27. Miah A, Reese CB, Song Q. Convenient intermediates for the preparation of C-4 modified derivatives of pyrimidine nucleosides. Nucleotides Nucleic Acids. 1997;16:53-65. https://doi.org/10. 1080/07328319708002521.

28. Ahlqvist GP, McGeough CP, Senanayake C, Armstrong JD, Yadaw A, Roy S. et al. Progress toward a large-scale synthesis of molnupiravir (MK-4482, EIDD-2801) from cytidine. ACS Omega. 2021;6:10396-402. https://doi.org/10.1021/acsomega.1c00772.

29. Cox RM, Wolf JD, Plemper RK. Therapeutically administered ribonucleoside analogue MK-4482/EIDD-2801 blocks SARSCoV-2 transmission in ferrets. Nat Microbiol. 2021;6:11-8. https://doi.org/10.1038/s41564-020-00835-2.

30. Gopalsamuthiram V, Williams C, Noble J, Jamison TF, Gupton BF, Snead DR. A concies route to MK-4482 (EIDD-2801 from cytidine: Part 2. syniett 2021. 2021;32:326-8. https://doi.org/10. 1039/d0cc05944g.

31. Hu T, Xie Y, Liu Y, Xue H, Zhu F, Asia HA, et al. Convenient and cost efficient route suitable for one-pot synthesis of molnupiravir. Chem Rxiv. 2021. https://doi.org/10.26434/chemrxiv. 14208206.v1.

32. Burke A, Birmingham W, Zhuo Y, da Costa BZ, Crawshaw R, Thorpe $\mathrm{T}$, et al. A biocatalytic approach to a key intermediate for the synthesis of the COVID-19 experimental drug Molnupiravir. 2021. https://doi.org/10.26434/chemrxiv.13721692.v1.

33. Paymode DJ, Vasudevan N, Ahmad S, Kadam AL, Cardoso FS, Burns J, et al. Toward a practical, two-step process for molnupiravir from cytidine. 2021. https://doi.org/10.26434/chemrxiv. 13550537.v1.

34. Gopalsamuthiram V, Kadam AL, Noble J, Snead D, Williams C, Jamison TF, et al. Towards a practical, non-enzymatic process for molnupiravir from cytidine. 2021. https://doi.org/10.26434/ chemrxiv.14738109.v1.

35. Huey R, Morris GM, Olson AJ, Goodsell DS. A semiempirical free energy force field with charge-based desolvation. J Computational Chem. 2007;28:1145-52. https://doi.org/10.1002/jcc. 20634.

36. G.M. G DS, Halliday RS, Huey R, Hatr WE, Belew RK, Oslon AJ. Automated docking using a Lamarckian genetic algorithm and an empirical binding free energy function. J Comput Chem. 1998;19:1639-62. 10.1002/(SICI)1096-987X 19:14<1639::AID-JCC10>3.0.CO;2-B.

37. Padhi AK, Shukla R, Saudagar P, Tripathi T. High-throughput rational design of the remdesivir binding site in the RdRp of SARS-CoV-2: implications for potential resistance. Iscience. 2021;24:101992. https://doi.org/10.1016/j.isci.2020.101992. 